
A

$\begin{array}{llllllll}T & R & E & A & T & I & S & E\end{array}$ ON THE

I NOCULATION OF HORSES, FOR THE

S $\quad T \quad R \quad A \quad N \quad G \quad L \quad E \quad S$;

IN WHICH IS CLEARLY IAID DOWI,

THE MANNER AND TIME OF THE OPERATION;

T HE

PREPARATION NECESSARY PREVIOUS THERETO;

AND THE MODE OF TREATMENT

DURING THE CONTINUANCE OF THE DISORDER;

THE WHOLE DEING THE

Refult of long and repeated Experience.

\section{By $\quad \mathrm{R} I \mathrm{CH}$ A R D F O R D \\ O F BIR MIN G H A}

WHO HAS MADE TIE COMPLAINTS OF HORSES HIS STUDY FOR MORE TKAN FIFTY YEARS PAST.

$B$ I IR $M$ I $N$ G $H$ A $M$ :

TRINTED BY E. PIERCY, IN BULL STREET,

AND SOLD IS

J. JOHNSON, ST. PAUL'S CHURCH YARD, LONDON.

[Entered at Stationer's Hall.] 



\section{SUBSCRIBERS NAMES.}

A.

A.DAMS, Mr. Worcefter

A Adams, Nir. Daventry

Ainge, Mr. Yarmouth

Allcn, Mr. Hockley

Allcn, Mr. Samuel, Banbury Oxfordhire

Allen, Mr. Northamptonthire

Allen, Mr. Joleph, ditto

Allens, John Efq. Worcefte:

Alfton, Mir. Winfon-green

$\Lambda$ hford, Mr. Suffoll-ftrect

is.

Bateman, Right Honourable Lord Vifcount

Beache, Dr. Birminghan

Barrs, Mr. Thomas ditto

Barker, Mr. John, Cherry-ftreet ditto

Barlow, Mr. Edgbalton

Bayley, Mr. Surgeon, Shifnal

Baxter, Mr. Janzes Moor-ftreet, Birmingham

Barr, Mr, Surgeon, - ditto

Baldwin, Mr Sen. Shirley

Barton, Mr. John Colchill

Barber, Jamcs, Efq. Tipton

Bentley, Mr. Birmingham

Bedford, Mr. Samucl Birlingham

Bennet, Mr. Saltley

Beubow, Mr. Worceftr two copics

Bernccker, Mr. Birmingham

Ledford, Mr. I. Perfhore

Birch, 
x SUESCRIBERS NAMES.

Birch, George Efq. Hamplead two copies

Bingley, Mr. Five-ways

Bingham, Mr. John Birmingham two copies

Bingham, Mr. James ditto

Blakefley, Mr at Brunton, Forbes \& Co. ditto

Blount, Mr. Surgeon, Birmingham

Blunt, Mr. ditto

Bolton, Matthew Efq. Soho two copies

Bonney, Rev. Mr. 'Tanzer, Northamptonfhire

Bradburn, Samuel Efq. Birmingham

Brooke, Mr. Attorney ditto

Brothers, Mr. G. ditto

Brown, Mr. T. ditto

Brand, Mr. Jchn Gainfborough

Burrows, Mr. Walfall

Bullock, Mr. John-ftreet Birmingham

Burgefs, Mr. John Great Wigftone Liecefternire

Butler, Mr. Whitaker

Bullftrode, G. G. Efq. Worcefterfhire

Buchanan, Mr. Birningham

Burley, Mr. James ditto

Buck, Mr. Joreph Northamptonflire

Budd, Mr. J. D. Birningham

$$
\text { C. }
$$

Carles, Jofeph Efq. Handfworth fine paper

Capper, Peter Efq. Birmingham

Carver, Edward Efq. ditto

Capper, Mr. Bull-ftreet aitto

Cappe, Mr. Hockley

Cattle, Mr. Sen. Knowl-hall

Care, Mr. Northamptonfhire

Cappe, Rev. Newcome York

Cannop, Mr. Worcefter

Chancer, 
SU B S CRIBERS NAMES. xi

Chancer, Henry Efq. Jun. Vernon's Oak

Chace, Mr. Bull-ftrect Birmingham

Chambers, Mr. Yardley

Chance, Mr. New-hail-ftreet Birmingham

Chevafe, Mr. Surgeon Walfall

Chamberlain, Mr. at Hotel Birmingliam

Chew, Mr. Thomas Northamptonfhire

Chew, Mr. Jofeph ditto

Chambers, R. Fifq. Whitburme

Clay, Henry Efq. Birmingham

Clutton, Thomas Efq. Kinnerflcy

Clarke, Rev. Mr. Worcefter

Cockett, Mr. New-ftrect Birmingham

Cope, Mr. John druggift ditto

Cope, Mr. chymift ditto

Conqueft, Mr. New-hall-ftreet ditto

Cottrill, Mr. Samuel Deritend ditto

Cottrill, Mr. John Smallbrook-ftreet ditto

Cope, Mr. John Liquor-merchant ditto

Cooke, Captain Birningham heath

Cooper, Mr Handfworth

Corbett, Mr.

Cooke, Mr. T. Worcefter

Collins, Mr. William London, I fine \& I courfe

Cottrill, Mr. Walfall

Crofts, Mr. William Livery-ftreet Birmingham

Crookc, Mr. 'Thomas Haddington five copies

Crefhull, Mr. Square Birmingham

Crockett, Mr. Hanfworth

Curtis, Rev. Mr. Birmingham

D.

Davis, David Efq. Pipe-hall

Dalley, Mr. London

Daris, 
Davis, Mr. Barr

Davis, Mr. Edghafton-ftreet Birmingham

Darwall, Rev.Mr. ditto

Danks, Mr. Oldbury

Darby, Mr. Danicl Birmingham two copies

Deykin, Mr. Bell Wood-ftreet London

Dearman. Mro.John Petty

Dixon, Mr. Düdley.

Dison, Mr. Barr

Dobbs, Mr. T. King's Norton

Dolphin, Mr, Surgeon Birningham

Dolpuin, Mr. Sen. New-ftreet Birmingham

Dowler, Mr. Great-charles-íreet ditto

Button, MIr. Hagley-row

$$
\text { E }
$$

Eclwards, Mir. Caftle Inn, Birmingham

Edwards, Mr. John

Egginton, Mr. Jun. Handfworth

Egrinton, Mr. Francis Handfworth

Ellis, Mr. Thomas Oundle, Northamptonfhire

Ellis, Major Worcefter

Iverton, Mr. John Birmingham

$$
\mathrm{F}
$$

Fletcher, Mr. Hedgford

Forbes, Mrr Alexander, Birmingham

Forbes, IIr. John, Birmingham

Ford, MIr. Colefhill-ftreet, ditto

Forreft, Mr. St. Paul's fquare, ditto

Lreer, Mr. John jun. furgeon, ditto

Freer, Mr. John fen. ditto

Frcer, Mr. Jhomas, druggift ditto

Trancin, Mr. William Moat ditto

irecme, Mi. William Worcefcr 
SUBSCRIBERS NAMES. xiii

G

Garbett, Francis Efq. Herefordmire

Gayd, Mr. Garnet

Geant, Richard Lfq. Handfworth

Gill, Mr. Thomas Birmingham

Gilby, Dr Birmingham

Gibls, Mr. Birmingham

Gimblett, Mr. John Birmingham

Glaze, Mr. Friday-freet, Birmingham

Goodbehere, Mr. Birmingham

Godwaltz, Mr. Birmingham

Gorge, Mr. Worcefter

Green, Jofeph Efq. Birmingham

Gregg, Mr. Samuel Birmingham

Gray, Mr. William, New-frect, Birmingham

Griffiths, Mr. Lirmingham-heath

Greaves, Mr. New-hall-1treet, Birmingham

Green, MIr. John, New-ftrect, Birmingham

$\mathrm{H}$

Hanfon, Mr. Smethwick

Halford, Mr. H. Weft-bromwich

Hawkins, Mr. Wm. Edmund-ftreet, Birmingham

, Hand, Mr. Heycock Green

Hammerfley, Rcv, Mr. Birmingham

Hackett, Andrew Efq. Moxall

Haynes, Mr. Worcefter 2 copies

Hardware, Mr. Bull's-head, Weftbromwich

Haynes, Mr. Northamptonthire

Hart, Mr. Edward Swan Inn, Birmingham

Hands, Mr. Samuel Birmingham

Haniley, Mr. William Kcnilworth

Hall, Mir. Market-Harborough

Hector, Mr. Birmingham

Herbert, 
xiv SUBSCRIBERS NAMES.

Herbert, Mr. William, Birmingham

Hewett, Rev. Mr. Northamptonthire

Hewfon, Mr. John Oundlc, Northamptonfnire

Hicks, Mr. Digbeth, Birmingham

Higginfon, Mr Paradife-row, ditto

Hinchley Mr. jun. ditto

Hodgkinfon, Mr. Northampton

Hooper, Mr. Afton

Homer, Mr. New-hall-ftrect, Birmingham

Huffey, Mr. John ditto

Huffey, P. Efq. Little Wyrlcy near Lichfield

Hunt, Mr. T. Corn-factor

Hunt, Thomas Efq.

Humphries, George Efq. Birmingham

Hyatt, Mr. New Caftle-under-Line

I

Javins, Mr. B.

Iddins, Mr. Birmingham-heath

Ingram, Thomas Efq.

Johnftone, Dr. Birmingham

Johnfon, Mr. C. Bull-ftreet, ditto

Johnfon, Mr. C. at Mirs Robins's Newftreet, ditto

Jones, Mr. E Livery-ftables, ditto

Jones, Mr. Jancs Birmingham

$\mathrm{K}$

Keir, James Efq. Tipton

Keay, Mr. Beekes, Smethwick

Kennedy, Mr. Surgeon, Birmingham

Kettle, John, Efq. ditto

Kilby, Mr. James Birningham.

King, Mr. Colmore-row, ditto

Kinder, Mr. Willam Stafford

Landei. 
I.

Landel, Mr. Edmund-ftreet, Birmingham

Lane, Rev. Mir Handfworth

Lawrence, Mr. Charles London

Lawrence, S. Bull ltrcet, Birmingham

Lake, Sir JamestVinter Bart. Edmonton, Middlcfex

Lewin, Mr. Furricr Market-harborough

Lord, Mr. Edward Birmingham

Lowdell, Jofeph Coventry, Efq. London

Lowdell. Ifaac Efq ditto

Lloyd, Mr. Hen and Chickens Inn. Birmingham

M

Montagu, his Grace the Duke of I 6 copies

Marfton, Mr. Paradife-row, Birmingham

Malkin, Mr St. Paul's-\{quare ditto

March, W. M. D. Coventry

Marindan, Mr. Cannon-ftreet, Birmingham

Mainwairing, Mr. A. Attorney, ditto 2 copics

Male, Mr.

Mafon, Mr. Temple-ftreet, Birmingham 2 copies

Martin, Nrr. Thomas Northamptonfhire

Male, Mr. J. Handfworth

Mardin, Mr. F. London

Mander, Mr J R. Birmingham

Mafters. Mr. Stalford,

Mcad, Mr, Wm. heal groom to Lord Dartmouth

Meadows, Mr. Lionel-ftreet, Birmingham

Merry, Mr. Temple row, ditto

Mnore, Samuel Efq. London

Mols, Mr. Lirmingham

Montague, James Efq. Equery to his Majefty

M ynors. Mr. Surgcon, Birmingham

Mynd, Mr. Thomas ditto

Nexwham 
«i SUESCRIBERS NAMES

Newnham, Counfellor

Newbold, Mr. William Dirmingham

Nevil, Mr. Charles, ditto

$\mathrm{O}$

Orton Mr. Birmingham

Oßborne, Mr. G. Barkfwell

Palmer, Mr. Maxftock

Palmer, Mr. C. Attorney, Colenill

Parrott, Francis, M. D. Birmingham

Parker, Mr. B. Attorney, ditto

Parker, Mr. Jofeph Coventry

Parkes, Mr. R. Brickiln-lane, Birmingham

Parkes, Mr. E. Birmingham

Parkes, Mr. Exeter-row, ditto

Parrock, Mr. Worcefter

Pemoerton, Mr. Snow-hill, Birminghan

Perry, Mr. M. Upper-priory, ditto

Perrott, G. Efq. Perhore

Piercy, Mr. E. Bull-1treet, Birmingham

Pickering, Mr. Winfon'green

Plafters, M J. Worcefter

Power, Mr. C. Colmore-row. Birmingham

Powell, Mr. Gofty-green, ditto

Powell, Rev. Mr. Rector of Church Lawford

Pritchard, Mr General Hofpital

Price, Mr. Theodore Birmingham

Priefley, Rev. Dr. ditto

Price, Mr. Lichfield-ftreet, ditto

Price, Mr. John ditio

Purton, Mr. Attorney, Sutton

Pywell, Mr, T. Northamptonfhire

Richards 
$S U B S C R I B E R S$ NAMES. wi

$\mathrm{R}$

Richards, MIr. T. Birmingham

Richards, Mr. Theophilus ditto 2 copies

Richards, Mr. Wm. Ncw ftrect, ditto

Richards, Mr. Sheldon

Robinfon, Mr. Eafy-row, Birmingham

Rofe, Mr. Great Charles-ftrect, ditto

Roberts, Major Dragoon Guards

Rokeby, Rev. Mr. Biddlefden-park, near Brackler,

Robins, Mr. King's-norton

Robbins, Mr. Attorney, Stourbridge

Roe, Mr. Frankley,

Rowe, Rev. Mr: Shrew fbury

Rufton, Mr. Joleph.

Ruff, Mr. John Oundle, Northamptonfin ire

Rutter, Mr. Love-lane, Londôii 4 copies

Ryland, Mr. S. Jun. Birmingha $m$

Ryland, Mr. S. Sen. New-ftreet, ditto

Ryland, Mr. Jun. High-ftreet, ditto

$S$

Sanders, Mr, Northa mptonflirc

Shenftone, Mr, Oldbury

Shaw, Counfellor

Sherratt, Mr. Birmingham

Sharp, Mr. John ditto

Simms, Mr, Gun-maker, ditto

Simpfon, Mr. Green-lanes

Sketchley, Mr. Moor-ftreet, ditto

Smart, Mr. Wolverhampton, 6 copies

Smith, Mr. Joln Coach Maker, Birmingram

Smith Mr. Wm. Colmore-row, ditto

Smith, Mr. New-hall-ftreet, ditto

Smith, Mr. Temple-ftreet, ditto

c

Smalbroke 
xviii SUBSCRIBERS NAMES.

Smallbroke, The Worhipful Richard. I. L. D. Chancellor of the Diocefe of Liclificld and Coventry

Smith, Mr. G. Northamptonflire Snape, Mr. Moxall

Stanley, Mr. Boughton-hall

Story, Mr. D. Birmingham

Stretton, Mr. Warfon-lane, ditto

Startin, Mr. New-hall-ftect ditto

Stirtin, Mr. jun. Snow-hill, ditto

Startin, Mr. Charles ditto

Summers, Mr. Bull-ftreet ditto

Spooner, Mr. Horfe Infirmary, ditto

$\mathrm{T}$.

Taylor, John Efq.

'Taylor, Mr. General Hofpital

Taylor, Mr, James New-hall-ftreet Birmingham

Taylor, Rev. Mr. John Park-ftreet ditto

Tabberner, Mr. Shirley

Tebbat, Mr. Sander

'Thomafon, Mr. Colemore-row Birmingham

Tibbats, Ambrofe Efạ. Sterlingghire

Timmins, Mr. Jantes

Tomlinfon, Mr. Surgeon Birmingham

Tonks, Mr. Peter Stonall

Twanley, Mr. Sutton

Vaughton, Roger Efq.

$$
\text { V. }
$$

Vaux, Mr. Surgeon Moor-frreet Birminglian

Vickers, Mr. ditto ditto

Villers, J. Efq. Handfworth

$\mathrm{U}$.

Undrill, Mr. Newton-ftreet Birmingham 
SUBSCRIBERS NAMES, xix

\section{W.}

Walcott, William Efq. Oundle, Northamptonfuire

Walcott, Dr. ditro

Waldron, N.Ir John Attorney Frankly

Ward, Mr. Bull ring Birminglram

Ward, Mr. John Jun. ditto

Ward, Mr. John Scn. ditto

Walker, Mr. William Sand-ftrcet ditto

Weftwood, Mr. John

ditto

Welch, Mr. Wiliam Jun. Colmore-row

Webb, Mr. Bell-Areet

Webner, Mr. Richard

ditto

Wells, Mr. Shirley

Whecley, Mr. Woreefter

Whately, Mr. Henry

Whateley, Mr. John

Whateley, Mr, John Birmirgham

Wheeley, Mr. Franeis ditto

Whitaker, Mr. Worcefter

Withering, William M. D. Birmingham

Wilkin, Mr. Worcefter

Willmore, Mir. Surgeon ditto

Wilbon, Mr. Farrier

Williams. Mr. Surgeon Rugby

Willetts, Mr. 'Thomas Birmin gham

Wright, Mr. Weft-bromwich

Wyatt, Mr.John

Yates, Richard Efq. London

$$
\text { Y. }
$$

York, Mr. John Surgeon, Oundle NorthamptonYoung, Rev Mir. St. Paul's Square, Birminghan 
1.

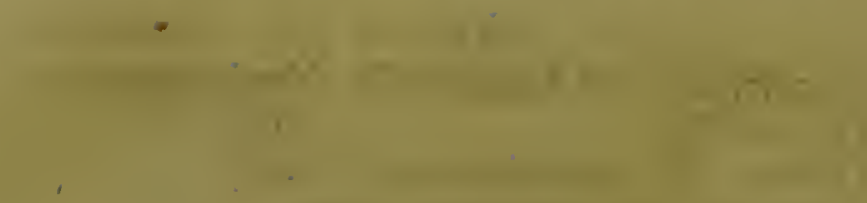

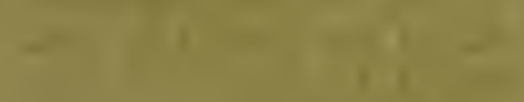

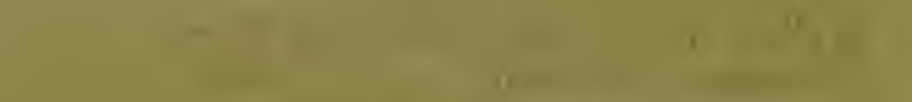

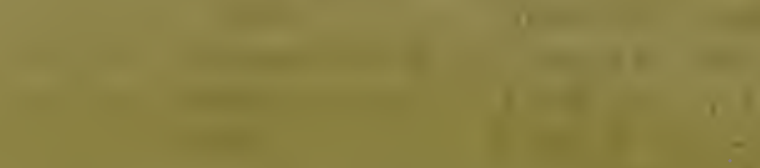

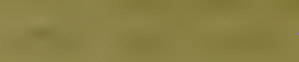
$x_{11}=1$

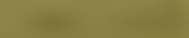
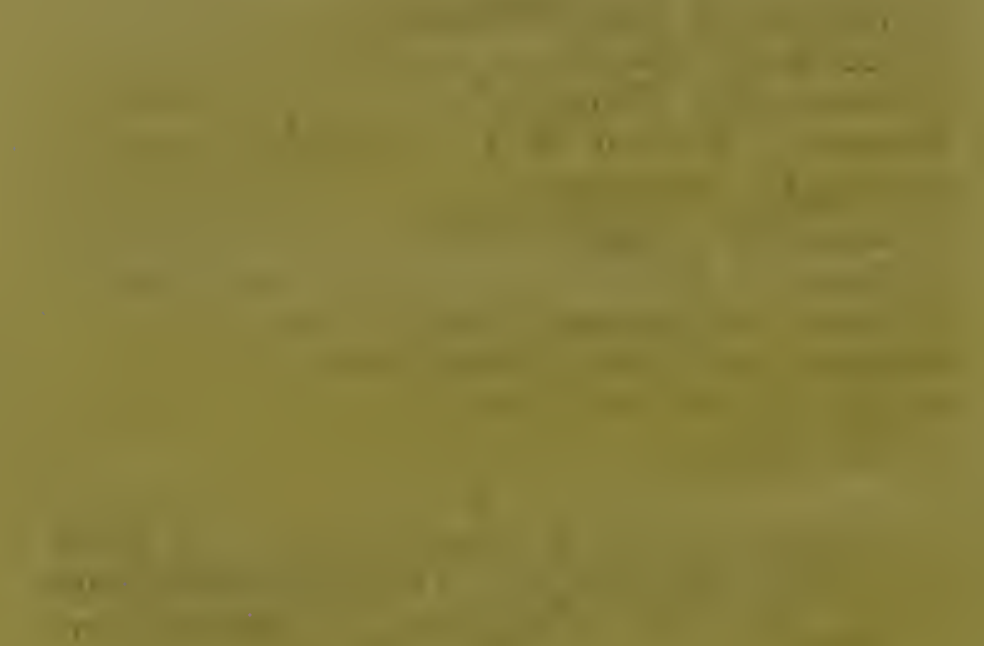
TO HIS GRACE THE MOST NOBLE

I HE DUKE OF MONTAGUE, MASTER OF THE HORSE TO HIS MAJESTL;

THIS SIALL TREATISE, WHICH HIS GRACE,

WITH A CONDESCENSION, AND PUBLIC SPIRIT,

$$
B E C O M I N G
$$

HIS ILLUSTRIOUS FAMILY AND EXALTED STATION,

$$
\begin{gathered}
\text { HAS BEEN PLEASED TO HONOUR } \\
\text { WI TH }
\end{gathered}
$$

HIS GENEROUS COUNTEN $\triangle N C E \triangle N D$ SUPPORT,

$$
\text { IS DEDICATED, }
$$

TVITH ALL POSSIBLE IIU MIIITY,

$$
\text { AND THE SINCEREST GRATITUDE, }
$$

$$
\text { BY HIS GRACE'S MOST DEVOTED, }
$$

AND MOST OBLIGED HUMBLE SERVANT,

$$
\text { THE AUTHOR. }
$$

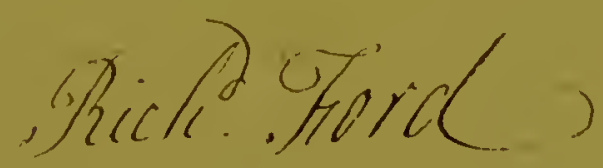




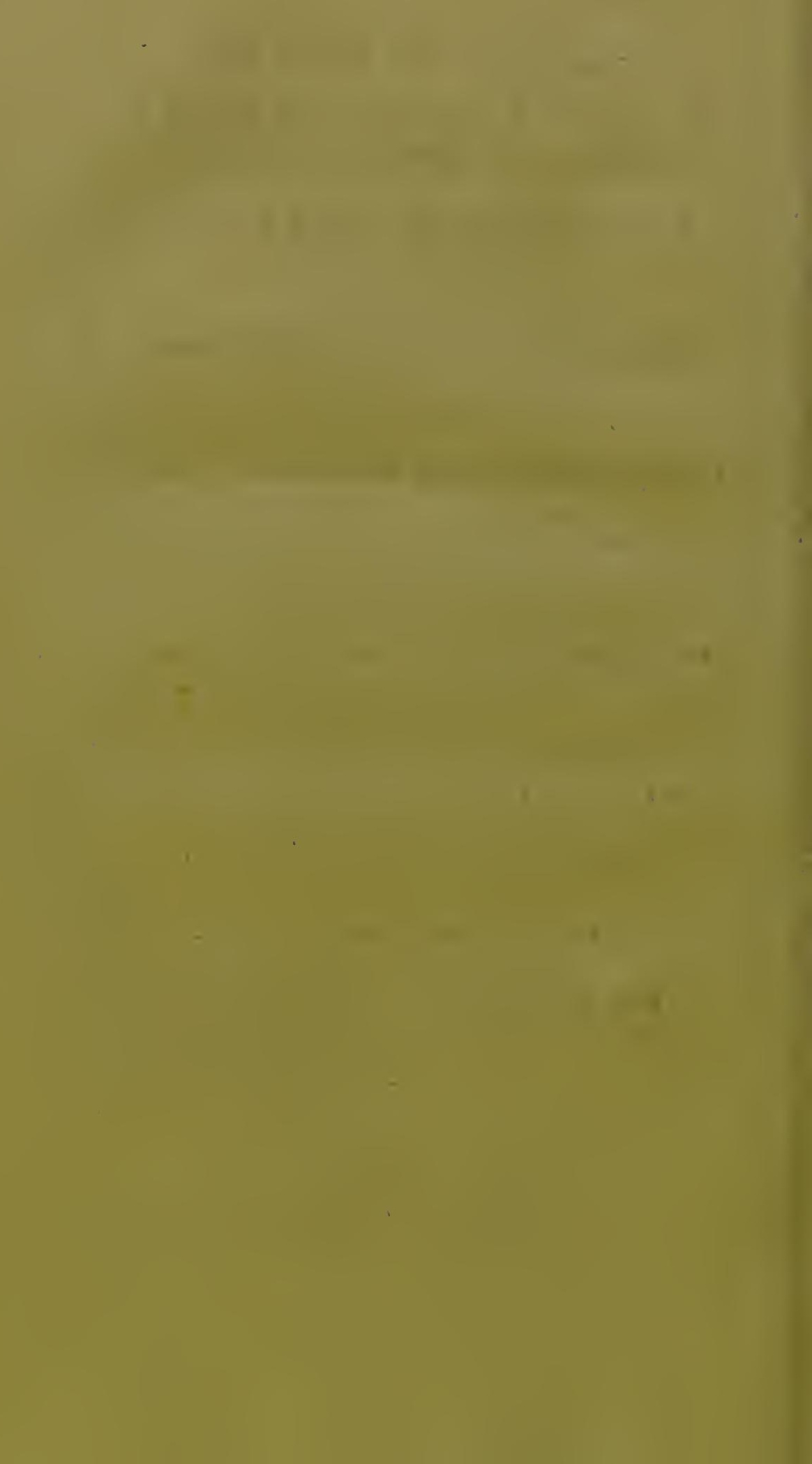




\section{$\begin{array}{lllllll}P & R & E & F & A & C & E\end{array}$}

E VERY endeavour to become ufeful to fociety, to whaterer branch of thofe arts which conftitute its chiefeft comforts and happinefs, our purfuits have been directed, fhould, if it does not raife us to any public teftimony of approbation, at leaft fecure us from uncandid and ill-natured criticifm.

The great utility of the prafice recommended in the following pages, and the advantages which may be derived from it, is the beft, and I hope, will be deemed a fufficient apology, for my offering them to the attention of the public. No wifh to acquire credit for uriginality, or novelty of thought, could have determined me, independent of the aloore confideration 
vi. $\quad P \quad R \quad E \quad F \quad A \quad C \quad E$.

confideration, to have commenced author.

A little reflection will be fuficient to make us fenfible, how many and great bleffings we derive from that mort ferviceable of all brute animals, the Horfe: and at the fame time will, I hope, perfuade to a juft valuation of them: for in whatever view we confider his fervices, whether in time of war or of peace, as fecuring to us thofe two effentials to all human felicity, Liberty and Health, they are equally apparent, and demand in return our fupport and care, and a humane attention to. all his fufferings.

It is much to be lamented, that the practice of Farriery has fo generally been hitherto confined to the moft 


\section{$\begin{array}{llllllll}P & R & E & F & A & C & E & \text { vii. }\end{array}$}

moft ignorant and illiterate part of mankind; yet cuftom has thrown a ftumbling-block in the way of removing it from fuch profeflors, by annexing fomething degrading to the ftudy of it.

In England this is particularly the cafe; nor is the encourarement here given to it, fuch as is likely to make it become a fubject of attention to perfons better adapted hy educa. tion to encreafe its advantages.

This neglect and contempt of a' futy fo highly beneficial to the community at large, and to every individual belonging to it, appears the more frrange in being thewn by the inhabitants of that foil and climate which produce horles of more real. value and excellence. than that of any 
viii. $\quad P \quad R \quad E \quad F \quad A \quad C \quad E$.

any other in the world. And this pre-eminence which nature has given us to boaft of, would, one might imagine, make us the more anxious to preferve and cherifh the indulgence.

Our neighbours, the French, arc far from treating the art of Farriery with difregard. They have erected public fchools, for the purpofe of infructing pupils in this art, to which lecturers are appointed by government to attend; where diffections are frequently made, and the difeafes of horfes, with their methods of cure, properly taught. If fuch encouragement was given to it in England, it is not to be doubted but it would turn to good account, as well on the fcore of humanity, as of national intereft. 


\section{A \\ $T$ R E A T I S E, Sc.}

THE Strangles is a diforder too well known to need any very particular defcription. It is marked by an inflammation and fuppuration of the fubmaxillary glands, attended with more or lefs general fever, cough, rumning at the nofe, \&c. It is highly contagious, and communicable by the fame means as other infectious diftempers.

Mr. Soleyfell has fuppofed it analagous to the fmall pox in the human fpecies, by obferving, that no horfe 


\section{$\left[\begin{array}{lll}2 & \end{array}\right]$}

is fubject to take the infection more than once. The power of tranfmitting it by inoculation, which I have invariably experienced, draws a ftill nearer parallel between the two diforders; yet the very diffimilar appearances they make in the two fpecies, the conftant locality of the one, and the general diffurion of the other, will not allow us to think them different modifications of the fame difeafe.

The Strangles has for its caufe, a fpecific poifon, which feems either to enter into the original conftitution of all horfes, or which they are predifpofed to generate, when expofed to certain fituations and treatment, favourable to its formation. Whichever is the cafe, the poifon is certainly deftroyed, or the difpofition to generate it is removed by the appearance of the diforder; fince no horfe

can 


\section{[ $\left.\begin{array}{ll} & 3\end{array}\right]$}

can be affected twice by it. It is a diftemper that all horfes are difpoied to, and there are few that efcape it. The common, as well as moft dangerous time for their having it, is during the breaking of them; and it always proves moft obftinate when it happens at this time, or to horfes of an advanced age, than in younger horfes, efpecialiy fuch as have not beell broke. This I think may be eafily accounted for, by confidering the treatment they are then fubjected to: the excelfive heats and fatigue they are made to fuffer; their being allowed to become cool fuddenly; the unnatural pofition in which the head is confined (efpecially of colts on the bit) by affeding the mass of humours in general, and the glands of the head and neck in particular, are fufficient to explain the caufe of the different degrees of danger attending this diforder before, and during, or A 2 


\section{$\left[\begin{array}{lll} & 4 & \end{array}\right]$}

after breaking. It cannot be doubted but that horfes fuffer much injury by the violent treatment offered them during this procefs, fince many difeafes are the vifible and immediate confequences of it; fuch as the farcin, greafe, \&cc. In no cafe can it ever be neceffary; and in general, encouragement will do more than feverity. Nor are their tempers lefs affected by this treatment than their natural corifitutions; and both may be truly faid to be broke, many being rendered dull and difpirited by it, that would otherwife have made active and valuable horfes.

The moft defirable time, therefore, at which horfes can have the Strangles, is, whilf they are young, and before the breaking of them; and this conficeration induced me to endeavour to find out 


\section{$\left[\begin{array}{ll}5 & 5\end{array}\right]$}

fome fafe and effectual method of communicating the diftemper to then at this tine. There were alfo other motives I had for wifhing to accomplifh it, independent of the lefs degree of dan$\mathrm{g} \in \mathrm{r}$ attending this diforder in young. colts; which were, to prevent the great inconvenience of having horfes attacked by it whilf on a journey (which I have more than once experienced) from confidering likewife that no time is lof, nor any expence incurred, by colts having it at an age when they are of no ufe to us. And again, that fhould it ever prove fatal, it is better to happen before the expence of three or four years ufelefs keep is beftowed upon them.

I am happy in having it in my power to fay, that I have been fuccefsful beyond my expectation; for as well as A 3

being 


\section{$\left[\begin{array}{lll} & 6 & ]\end{array}\right.$}

ieing able to communicate the diforder whenever I have wifhed, the means which I have ufed for doing it, have conftantly produced it in a much flighter degree, than when it is caught in the natural way; and this I have effected by Inoculation.

All horfes in health are proper fubjects for Inoculation; but foals or colts are the moft fo; and many advantages will attend the performing the operation at an early age, as well as the important one of fecuring them from taking infec. tion by the natural means.

I have inoculated horfes at all ages; from two days old, to feven years, and have always obferved that the younger the fubject was (provided it was healthy) 


\section{$\left[\begin{array}{lll}1 & 7\end{array}\right]$}

the more favourable every fymptom of the diforder appeared. Out of two hundred colts on which I have performed this operation, not one has died; and I am encouraged by this to hope, that the practice which I here recommend, will, when known, be generally adopted.

For the reafons before given, I would advife the operation to be done at an early age, and would prefer inoculating the foal whilf it fucks of the mare, to any other time; and in this cafe, the earlier the infection is given the better: which may be fafely done at a month or fix weeks old. For towards the latter end of the year, the quantity of the mare's milk is leffened, and during this diforder the foal may not take to graz. ing; or if it fhould, the grafs does not afford that nourifhment at this feaA.4 ron 


\section{$\left[\begin{array}{ll}8 & 3\end{array}\right.$}

fon which it does in the fpring and funmer.

It frequently happens too, that foals, efpecially thofe which thrive apace, grow lean about the time they leave the mare and take to grazing, when inoculation would not be advifeable, and had better be deferred till the following fpring. Another reafon why I would recommend the operation to be performed at an early age, is, the thinnefs of the fkin ; for as the diforder is more naturally and effectually carried off by the formation and breaking of an abfcefs, lefs difficulty is likely to occur at this time, than whien the fkin by becoming thicker, is capable of giving greater refiftance to the matter to be evacuated: by which the cure may be protracted. 


\section{$\left[\begin{array}{ll}1 & 9\end{array}\right]$}

The ligher in health the colt is, the fonner matter is formed, and the diforder terminated ; as a certain degree of inflammation is neceffary for that purpofe, which fickly and. weak colts are not difpofed to. Fodls and colts which are healthy and at grafs, require no preparation previous to giving them the infection; but horfes which have been long kept in the ftable, and are intended to remain there during their having the diforder, it may be neceffary to prepare, and this will chiefly confit in emptying the ftomach and inteftines of any foulnefs which may have been generated there.

To anfwer this purpofe, I have ufually given half a drachm of calomel well levigated with double the quantity of prepared chalk, and made up into a ball, with conferve of hipps in the evening; and 


\section{$\left[\begin{array}{lll}1 & 10\end{array}\right]$}

and a folution af a pound of Epfom falts on the following morning. This is the ufual dofe, but muft be varied according to the frength and habit of body of the horfe it is intended for. It flould be repeated three times within the fortnight preceding inoculation, and the laft dofe given on the fame day the operation is performed.

Having determined the moft proper and advantageous time for inoculating, and the preparatory treatment of fuch horfes as may require it, the next thing to be confidered, is, the place and method of performing the operation. Thefe I have frequently varied, and have found none fo convenient and fuccefsful, as the following, which I now conftantly practife.

I makc 


\section{[ II ]}

I make an incifion on the infide of the upper lip, about an inch from its junction with the lower one, and at equal difances from its outer edge, and where it attaches itfelf to the gum. This incifion is beft made with a lancet, fuch as is generally ufed in bleeding of horfes, which is to be introduced at the place before directed, immediately under the fkin, and which may be eafily done by inverting the lip, and holding it tightly turned with the left thumb and finger over the under part of the fame hand. When the lancet is introduced to about the depth of half or three quarters of an inch, the point of it is to be moved on each fide, in fuch a manner as to make the bottom of the wound wider than its orifice, which latter needs not be larger than the lan-: cet requires for its infertion. When the incifion is thus made, I take a fmall piece of 


\section{$\left[\begin{array}{lll}12 & 12\end{array}\right]$}

of lint, or fine tow, impregnated with the infectious matter, and with a probe introduce it into the wound beyond its edges, fo that no part of it be fuffered to hang out, otherwife it may be thrown out again immediately, by the action of the lip againft the teeth and gum. The lint I fuffer to remain in the wound till it is difcharged either by accident or by fuppuration. I have preferred the upper lip to the lower one for making the incifion in, on account of the dependant fituation of the wound, thereby preventing any future mifchiefs which might arife from a lodgment of the lint or matter.

In one of the colts which I inoculated in the under lip, an abfcefs was formed, which difchargeả itfelf exteriorly, leaving a hole quite through the lip; but no accident of this kind has happened 


\section{$\left[\begin{array}{lll} & \text { I3 }\end{array}\right]$}

happened when the incifion was made in the upper one. The right fide of the lip will be found more convenient than the left.

There are many methods of applying the infectious matter.

It may, be done by charging a lancet with it, and fimply puncturing the infide of the lip; or the matter may be inferted into the wound (in the manner before directed for the lint) in a concentrated ftate; and is procured by catching it from the glands of a diftempered horfe, in a glazed bafon or glafs verfel, and fuffering it to infpiffate without heat into a gluey or horney confift-. ence, in which fate it will remain active, if well fecured from the air, many months, 


\section{$\left[\begin{array}{lll}14 & ]\end{array}\right.$}

months. But the way I would recommend, as being the moft fure and effectual, is by means of prepared linit, as I have before direcled.

The matter that is made ufe of for charging this lint, thould be taken from the Strangles of fome young horfe, in which the diforder has not been of long ftanding; for it is to be obferved, that the matter is efficacious in proportio: to the early ftate of fuppuration in the abfcefs from which it is taken. In this matter the lint is to be dipped, and fhould be kept for ufe in a well corked phial in a damp place, where it will remain good a long time. After fome time keeping it will loofe its moifure, and become dry, when, if occafion offers for ufing it, it may be held over the team of warm water for about a minute before 


\section{[ 15$]$}

before it is applied; yet this is not abfolutely neceffary to be obferved, as the warm blood from the wound will anfwer the intent of the fteam in fetting at liberty the active particles of the matter.

In two or three days after inoculation, the lip will begin to inflame and fwell; and in feven or eight days more, the glands under the jaw will be affected in like manner. There will continue fwelling for about a week, and will generally be attended with fever, cough, and a difficulty of fwallowing. In about three weeks from the operation, matter will begin to be formed under the lower jaw, and moft frequently on the fame fide as the lip inoculated. In lefs than a week more, fuppuration will have fully taken place, as will be evident by the loofenefs of the hair covering the fwel-

ling, 


\section{$\left[\begin{array}{lll} & 16 & ]\end{array}\right]$}

ling, the oozing of matter through the fkin, and the fluctuation to be felt on touching it.

In this flate it may be fuffered to remain for two or three days, but if a difpofition to break fhould not be obferved, and the fkin covering it fhould ftill remain thick, it will be proper to open it.' This opening fhould be made lengthways with a fmall knife, or lancet, the whole extent of the abfcefs; the contents of which are to be preffed out, and the wound is to be dreffed with yellow bafilican, or a digefive compofed of equal parts of olive oil, horfe turpentine, bees-wax, and honey, boiled together, fpread upon foft tow, and inferted down to the bottom of the wound, which is to be kept open, by this manner of dreffing till the difcharge begins 


\section{$\left[\begin{array}{lll}17 & 1\end{array}\right]$}

to abate; for if it is fuffered to heal too foon, other abfeeffes will be forned in the adjacent glands, and fometimes in different parts of the body. A rumning at the nofe too, which is a difagreeable, and frequently a dangerous tymptom, may be prevented by this treatment.

Though I have recommended an opening of the abfcefs to be made, yet care is to be taken that this is not done before the matter is compleatly formed in it, otherwife the lips of the wound, as well as the glands themfelves will become hard and callous, and require perhaps a fecond operation before it can be healed. On the other hand, the natter fhould not be fuffered to remain too long confined, for in this cafe, by infinuating itrelf among the glands, and between the interfices of the mufcles, it will form 


\section{$\left[\begin{array}{lll}18 & 18\end{array}\right]$}

finuffes which may afterwards prove tedious and troublefome to cure, or by making its way down to the bone may render that foul and carious.

If any very great degree of fwelling fhould occur, attended with much difficulty in sreathing or fwallowing, yet no difpofition to fuppurate fhould appear, a poultice made of a ftrong decoction of linfeed and marfh-mallows, boiled up with oatmeal, to a proper confiftence, to which a little ointment of elder is added, may be applied to the throat every night and morning, will in general procure relief, by haftening the formation of the abfcefs, and when that breaks, the difficulty of breathing, \&c. will be removed, and nothing more will be required than gnod feeding and a dry fituation. 


\section{[ 19 19 $]$}

Horfes which are fuffered to remain in the field after Inoculation, and during the progrefs of infection, do much better than thofe which are confined in the fable; and bere they require very feldom either medicine or affiftance.

Nothing is more 'likely to procure a favourable termination of the diforder, than the preferving the temperament of the body during the inflammatory ftage, in as near a ftate to that of health as may be. And nothing conduces more to this, than grafs, and a conftant expofure to the air: nor do I know any diforder in which their good effects are more vifible than in the Strangles; fo that I would wifh particularly to recommend their being always allowed to remain in the field, except the extreme $\mathrm{B}_{2}$. coldners 


$$
\text { [ } 20 \text { ] }
$$

coldnefs or inclemency of the weather thould forbid it.

Bleeding, in any ftage of this diforder, Should be always if poffible, avoided. I have had many occafions of witneffing the danger attending it; and it will certainly be found that whereever it is practifed, the recovery will at leaft always prove tedious. It fhould therefore never be thought of, but when there is fear of fuffocation; which is an accident n'st likely to happen to thofe horfes which are kept out of doors.

The fever which is raifed by the introduction of the virurent matter, if it fhould be ton immoderate, is beft refrained by fmall and repeated dofes of James's 


$$
\left[\begin{array}{lll}
{[} & 2 & 1
\end{array}\right]
$$

James's antimonial powder; to which if there fhould be much cough, an opiate may occafionally be added. After the abfcefs is healed, two or three dofes of purging phyfic will be advifable,

The directions before given, will be found fufficient for inoculated horfes in general, and will be all that are neceffary in , noft cafes.

There are, however, fome other fymptoms befides thofe I have mentioned, that may appear; but as they do not fpecifically belong to the Strangles, but to many other diforders in common with it, I have not thought it worth while to encreafe thefe few pages by an enumeration of them; efpecially as the treatment of them may be léarned betB 3 ter 


\section{$\left[\begin{array}{lll}1 & 22 & ]\end{array}\right.$}

ter from a fudy of difeafes in general, than of any one in particular. My chief plan has been to afcertain the undoubted fafety of inoculating colts, and to put it into the power of every perfon to perform that operation himfelf.

When I firf thought of giving an account of the experiments which I had made, with my fentiments of the diforder, I did not forefee the many caufes of delay and difappointment, that have attended it. An almoft conftant engagement in bufinefs, has precluded me the power of paying all that attention which the fubject fo well merits.

At fome future day, I hope to have it in . my power to add-mucl to it; but fhould any thing occur to prevent 


\section{$\left[\begin{array}{lll}2 & 3 & \end{array}\right]$}

vent this, I thall neverthelefs be happy in thinking, that I may have been the means of procuring it the attention of men of more leifure and greater capacity.

The defire I bave for not withholding longer a fecret of fucl importance from the public, and the hafte which this prompts me to, will I hope, apologize for my brevity, but had time permitted me to fwell this pamphlet out to what fome men would call a reafonable number of pages, it might perhaps, at laft, have not proved of more real value or utility.

\section{F $\quad I \quad N \quad I \quad S$.}




